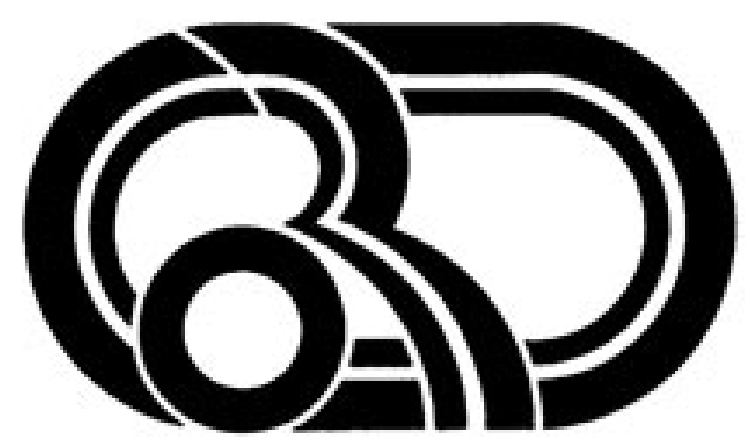

Technique and Theory in the Work of Kapila Vatsyayan

Author(s): Janet O'Shea

Source: Dance Research Journal, Vol. 32, No. 1 (Summer, 2000), pp. 82-86

Published by: University of Illinois Press on behalf of Congress on Research in Dance

Stable URL: http://www.jstor.org/stable/1478280

Accessed: $18 / 12 / 2008$ 12:10

Your use of the JSTOR archive indicates your acceptance of JSTOR's Terms and Conditions of Use, available at http://www.jstor.org/page/info/about/policies/terms.jsp. JSTOR's Terms and Conditions of Use provides, in part, that unless you have obtained prior permission, you may not download an entire issue of a journal or multiple copies of articles, and you may use content in the JSTOR archive only for your personal, non-commercial use.

Please contact the publisher regarding any further use of this work. Publisher contact information may be obtained at http://www.jstor.org/action/showPublisher?publisherCode=illinois.

Each copy of any part of a JSTOR transmission must contain the same copyright notice that appears on the screen or printed page of such transmission.

JSTOR is a not-for-profit organization founded in 1995 to build trusted digital archives for scholarship. We work with the scholarly community to preserve their work and the materials they rely upon, and to build a common research platform that promotes the discovery and use of these resources. For more information about JSTOR, please contact support@ jstor.org.

Congress on Research in Dance and University of Illinois Press are collaborating with JSTOR to digitize, preserve and extend access to Dance Research Journal. 


\title{
Technique and Theory in the Work of Kapila Vatsyayan
}

\author{
Janet O’Shea
}

As a scholar and practitioner of Bharatanatyam I would like, foremost, to express my gratitude to Kapila Vatsyayan for her comprehensive, in-depth studies of Indian classical dance forms. Her work includes attention to both distant and recent epochs in the history of Indian dance as well as to current practice. Her analysis of many divergent sources has laid the groundwork for any academic study of classical Indian dance. She not only provides an exhaustive account of Indian dance in the past and present but also interprets the relationship among aesthetic theory texts, historical dance practice, and contemporary, classical Indian choreography in a nuanced and sophisticated manner.

Because the strengths of Vatsyayan's research are manifold, I restrict my consideration here to a narrow focus. Specifically, this discussion focuses on her concept of dance technique as an integral part of her analytical framework. This essay also addresses the ramifications of her methodology for current and future work in the field of dance studies. In particular, I consider how Vatsyayan's understanding of the bodily subject offers an important paradigm for current writings within dance scholarship, especially those that interpret dance praxis in relation to social theory (1). Moreover, I limit my attention to two of Vatsyayan's major works: Classical Indian Dance in Literature and the Arts and Indian Classical Dance.

\section{Kapila Vatsyayan's Concept of Technique}

Vatsyayan theorizes the corporeal subject through the category of technique. She mobilizes the notion of technique for analytical classification of both the pedagogical and performative aspects of a particular dance form. This typology is a general one: it functions as a framework that incorporates a set of criteria for extracting the characteristic features of a system of stylized, bodily action. In Vatsyayan's paradigm, technique operates as a methodology for organizing movement.

Drawing upon her sustained research into classical aesthetic theory texts in the Sanskrit language, Vatsyayan locates her model, predicated on this notion that I refer to as the "technique concept" in movement vocabulary, dance syntax, and pedagogical exercises (2). Such an idea shifts the concept from a specific, descriptive term-that in North American dance parlance usually refers to dance training, such as in the phrase "dance technique class"- to a general, analytical frame. For instance, in her discussion of the technical features of Indian dance, Vatsyayan highlights the "building blocks" of contemporary dance forms, such as the adavu in Bharatanatyam, which function as both training exercises and the irreducible components from which performance choreography emerges. This consideration of technique links, in her writing, class exercises with all of the other constitutive elements of a dance form, including its expressive

Janet O'Shea has been a student and performer of the Indian dance form Bharatanatyam for the past ten years. A disciple of Smti Nandini Ramani of Madras, in the tradition of T. Balasaraswati, she studied the dance form in India under the auspices of the American Institute of Indian Studies. She holds an M.A. in Tamil from the University of California at Berkeley and is currently a Ph.D. candidate in Dance History and Theory at the University of California at Riverside. Her article "Traditional' Indian Dance and the Making of Interpretive Communities" was recently published in Asian Theatre Journal. Her essay on Shobana Jeyasingh received the Society of Dance History Scholars' 1998 Selma Jeanne Cohen Award. She is a lecturer in Dance History at the University of Surrey. 
portions (Vatsyayan 1992, 13). Vatsyayan uses technique, then, to trace a continuum between the daily practice of a dance form and its manifestation onstage.

Vatsyayan's approach to dance analysis extends beyond her vast knowledge of Sanskrit aesthetic theory texts to include the representative qualities that constitute a dance form, such as the dancing body's relationship to time, space, and gravity. For instance, basic stances from which movement originates are culled from texts and praxis, but Vatsyayan also adds such elements as the geometric patterns created by dancing bodies. Vatsyayan's studies encompass such factors as the relationship to a corporeal center and the movement vocabulary's division of the body into units.

Vatsyayan, however, moves beyond the Sanskrit texts that have influenced her work when she explicitly delineates not only sets of dance steps, floor patterns, and the organization of movements, but also the different body concepts that various dance forms cultivate.

\section{Technique and the Organization of the Dancing Body}

Vatsyayan's definition of technique, then, allows her to demonstrate how a dance form's characteristic units of movement constitute that form's particular way of interpreting the body. For Vatsyayan, this theorization of the body varies across movement forms. In discussing the commonalities among Indian classical dance styles, for instance, she extracts overarching priorities from the predominant movement components of each. She argues that the concern of Indian dance forms with the vertical median as point of initiation and return indicates a more general organization of the body around this centerline, demonstrating how all of these styles of dance privilege an upright, symmetrical body. Similarly, Vatsyayan maintains that Indian dance constructs the body around the articulation of joints in relation to one another, in contrast to Western dance, which views the body through the lines created by its musculature.

In her study of the relationship between movement priorities and the conceptualization of the body created therein, Vatsyayan does not restrict herself to similarities among Indian dance forms. She describes the dancing body of Bharatanatyam as consisting of lower limbs, thought of either as straight lines or as two sides of a triangle, arching upper limbs, and a torso that operates as a single unit (Vatsyayan 1992, 25). By contrast, she demonstrates how Odissi's use of a deflected hip and unequal weight on bent legs varies from the straighter positions typical of other types of Indian dance (Vatsyayan 1992, 60). The appearance of these movements in Odissi contributes to a different body concept than in other Indian dance forms. According to Vatsyayan, the Odissi body remains divided along a central median but also becomes characterized by curves arching into and out of asymmetricality (Vatsyayan 1992, 59).

\section{The Advantages of the Technique Paradigm}

Vatsyayan's recourse to technique as a general principle allows her to analyze the relationship of classical aesthetic theory to historical dance praxis. Through a comparison of a number of historical sources, for example, she clearly distinguishes likely components of older dance forms from the imaginative element of the text or visual image. This close attention to the types of movement featured in a variety of source materials enables Vatsyayan's clarification of the relationship between, in her terms, the expressionistic and notative aspects of dance texts and visual iconography (Vatsyayan 1992, 6).

Inspired by her translation work with Sanskrit aesthetic theory texts, Vatsyayan locates dance practice in the specifics of movement vocabularies, terminologies, and syntaxes. By linking this interpretation with the Laban analyst's ability to observe movement vocabularies through their component parts, Vatsyayan develops a model of dance analysis applicable to movement forms beyond those referred to by the Sanskrit aesthetic theory texts. Her technique paradigm, then, while rooted in classical Sanskrit works, has relevance for a wider range of movement forms. 
Vatsyayan unites her in-depth knowledge of Sanskrit aesthetic texts with her experience with Labanalysis to produce an understanding of dance as a conscious cultural practice that can be described verbally through its component features. This view, in turn, provides a way into articulating divergences and similarities in the construction of corporeality among different cultures or time periods. Vatsyayan's technique concept, then, has utility for any number of endeavors within dance scholarship.

This technique concept, as a result, has particular applicability to cross-cultural scholarship since it represents a point of entry into the academic study of any number of dance forms. Specifically, the recourse to technique as movement logic constitutes an equalizing maneuver. Rather than privileging one particular movement system as a norm, such a model enables scholars to approach dance forms of disparate cultures and time periods as distinctive means of conceiving of the body. Vatsyayan's paradigm also facilitates the interpretation of the cultural priorities evident in a dance form while not reducing dance to the status of reflecting its culture, time period, or social group. This methodological framework situates dance as an active cultural participant in relation to other systems of thought.

\section{Further Applicability of the Technique Model}

Vatsyayan's approach also speaks to some problems conventionally associated with dance scholarship. Because of my own research focus on Bharatanatyam in the United States and India, I highlight the academic study of dance in these two countries. Although the field of dance scholarship obviously extends far beyond specific intellectual practices in either the United States or India, a related set of problems that manifests in these two locations remains relevant for the subject area that Vatsyayan considers. As is by now well known, scholars outside the field have tended to view dance scholarship as a problematical and difficult venture. How can something that, apparently, leaves no trace be studied? More generally, dance has conventionally been associated in Europe and North America with irrationality, ineffability, and is often portrayed as unrepresentable. Dance studies has often countered these charges by explicitly developing means of theorizing the corporeal subject. Vatsyayan's concept of technique offers one such clear method for articulating the moving body. Her close analysis of movement qualities in materials beyond live performance, such as in textual description and visual iconography, offers a means to find traces of dance performance in historical evidence. It is not only the rigorous investigation of multiple sources, but also her very willingness to make manifest her comparative, cross-text, and cross-genre approach that rebuts the assumption that remnants of dance performance dissipate instantly.

In addition, Vatsyayan's technique concept transcends the common dichotomy between rationality and emotionality. By demonstrating how expressive dance forms consist of movement logic, her studies bridge a perceived gap in Western, and more specifically American, thought between intellect and sentiment. Vatsyayan's framework of dance analysis, therefore, circumvents assumptions about the ascribed ineffability of dance. As she illustrates how an analytical approach to ordering movement inheres in the dance forms themselves, Vatsyayan suggests that dance functions as a system of thought that can be interpreted through writing.

In India, by contrast, dance is held in higher regard than it has customarily been in the United States. Historically, authors have considered dance worthy of academic study, as evidenced by the numerous theoretical aesthetic texts which appear from the second century B.C.E. (Vatsyayan 1992, 1-2). The dichotomy between cognitive and emotive qualities or experiences does not have the same pervasive influence that it generally carries in North American thought. Nonetheless, some recent Indian dance scholars have tended to neglect embodied practice in favor of ancient aesthetic theory texts. A number of authors, for instance, have turned to texts such as the Natyashastra and the Abhinayadarpana but have stopped their investigation there (3). Because of the influence held by reconstruction projects, such as that of Rukmini Devi and other midcentury dance reformers, in the Indian classical 
dance milieu, some critics have been interested in evaluating contemporary classical dance forms according to Sanskrit aesthetic texts. Vatsyayan, however, adapts the theoretical bases of such texts-for instance, the analysis of dance through the delineation of units of movement and structural standards that govern the creation of phrases-to investigate live dancing.

Vatsyayan not only adjusts the fundamental premises of such works to the analysis of present-day movement forms but also distinguishes between the theoretical texts themselves and the dancing of the past to which they refer. She provides a sophisticated analysis of the texts, in which she extracts practice from aesthetic theory, rather than treating the written work as identical to historical praxis. For instance, in her discussion of the Sangita-Ratnakara, Sarngadeva's text on music, she persuasively argues that the author's emphasis on regional variations from a standardized dance classicism suggests both the influence of prescriptive texts and the departures from them in local practice (Vatsyayan 1992, 6). In addition, she supplements her study of the better-known texts with other treatises on the aesthetic experience, with references to dance in Sanskrit poetry, drama, and epics, and with a myriad of visual source materials, such as painting and sculpture.

Finally, Vatsyayan also investigates the role of temporal change in Indian dance. Rather than argue that contemporary classical dance remains wholly faithful to the tenets of ancient aesthetic texts or that it has completely diverged from its historical sources, she convincingly demonstrates that concert dance in India today represents an intentional reconstruction of earlier practice. In her view, then, the present-day classical dance forms both reflect a modem sensibility and engage actively with "fragments of antiquity" (Vatsyayan 1992, 8). At the same time, Vatsyayan expresses a profound respect for the enduring vitality of the oral traditions from which contemporary dance praxis emerges (4).

\section{Application of the Technique Concept to Social Theory and Dance Analysis}

Vatsyayan's endeavor bridges a perceived discontinuity between "theory" and "content," a common perception that scholarship need be divided into "theoretical" projects, meaning those that engage in a methodological discussion, and "content-based" studies that provide specific information. A prevalent understanding is that one of these endeavors must happen at the expense of the other: those works concerned with content forgo theoretical investigations while "theory," which closely examines academic approaches, neglects factual material. Vatsyayan's work, supplants this dichotomy as it cultivates both compendia of information and a strong analytical model. Her notion of technique, in particular, encourages both the description and analytical interpretation of component parts of dance forms.

Much new research in dance studies has urged the interpretation of dance in relation to broader social and cultural factors, institutions, and practices. Vatsyayan herself portrays dance as constituted by internal logic systems and also demonstrates how the dancing actively engages with areas of cultural life such as religion or with related arts such as literature. Thus, her analysis provides a model for those interested in linking the specifics of dance practice with larger social life as she suggests that the elements of dance form a continuum with more general cultural and social considerations. A major purpose in focusing attention on "theory" lies in an interest in increasing the relevance of particular studies beyond their own field and, more generally, in fostering cross-genre and cross-disciplinary exchanges. Vatsyayan's model represents one such example of a methodology applicable beyond its immediate subject matter. In fact, as I argued above, this idea of technique as movement methodology may be useful for understanding any form of intentionally stylized bodily action.

While dance scholarship has generally analyzed the dancing body as a site of cultural and societal discourse, many approaches have also interpreted corporeal subjects not only as locations of cultural production but also as active participants in their surrounding world. By indicating how the tools of analysis emerge from the dancing 
itself and by drawing her methods out from Sanskrit theoretical texts into a potentially cross-cultural system of interpretation, Vatsyayan's model offers a moving body that not only is inscribed within a culture, but also plays an active role within that culture. For these, and many other reasons, I, and nearly every scholar writing on Bharatanatyam, have found Vatsyayan's analyses of Indian dance to be indispensable. Kapila

Vatsyayan's research has strongly influenced subsequent works not only because of the great deal of information she imparts but also because she offers a paradigm that considers Indian dance, and dance in general, as a conscious practice that intersects with broader cultural concerns and negotiates with historical flux.

\section{Notes}

1. Because of the varying terminologies involved in Indian and American dance scholarship, I use the term "theory" in two different ways in this essay. The first sense, in currency in U.S. dance studies, uses "theory" to refer to inquiry that depends upon and arises out of poststructuralist thought, including such fields as Marxian analysis, postcolonial studies, and feminist theory; this, I refer to as "social theory." The second connotation of the term, used largely in Indian dance research, refers to classical texts, mostly written in the Sanskrit language, which study dance and drama forms through aesthetic analysis. This second sense of the term I convey through reference to "aesthetic theory."

2. I am indebted to Uttara Asha Coorlawala for urging me to incorporate an etiology of Kapila Vatsyayan's insights into this study.
3. Kapila Vatsyayan makes note of a similar problem in her 1995 essay,"The Future of Dance Scholarship in India." She comments, "Valuable as the first three [dance theory texts, visual iconography, and music] are, all relate only to the groundwork and the structural periphery of the dance.... Too often dance scholarship on movement becomes a narrative of life histories of dance masters, regions, and styles. It does not go into the system of articulation of movement"(486).

4. For example, at the October 1998 CORD conference at which Kapila Vatsyayan's contributions to dance scholarship were honored, Dr. Vatsyayan spoke fondly and with great respect of her training with a number of the masters of the oral tradition of Indian classical dance forms. In addition, she emphasized that the reconstruction projects, which constitute a great deal of choreography and performance work in contemporary classical Indian dance, emerge as much out of continous praxis as they do out of aesthetic texts.

\section{References}

Vatsyayan, Kapila. Indian Classical Dance. New Delhi: Publications Division, Ministry of In- in Literature and the Arts, 2nd ed. New Delhi: formation and Broadcasting, Government of In- Sangeet Natak Akademi, 1977. dia, 1974. Reprinted, 1992.

"The Future of Dance Scholarship in India." Dance Chronicle 18, no. 3 (1995): 485-490. 